\title{
PROTECTIVE ROLE OF ROYAL JELLY TO ALLEVIATE SIDE EFFECTS OF CHEMOTHERAPY ON SUBMANDIBULAR SALIVARY GLANDS OF ALBINO RATS (HISTOLOGICAL AND ELECTRON MICROSCOPIC STUDY
}

\author{
Nehad A. Ahmad* and Noura M Bakr*
}

\begin{abstract}
Chemotherapeutic agents often have severe tissue injury and cytotoxic effect. Royal jelly has beneficial biological effects, such as anti-inflammatory, antitumor, anti-allergic, and antioxidant activities on various cell types.
\end{abstract}

Aim: The purpose of this study was to evaluate the protective role of royal jelly on cytarabine induced cytotoxicity on submandibular salivary glands of albino rats.

Methods: 21 male albino rats weighing between 220 and $250 \mathrm{~g}$. were divided equally into three groups. Group I (control group) normal without any medication. Group II (cytarabine group) at dose (100mg/kg/ I.P). Group III (cytarabine \& Royal jelly group) was administrated royal jelly prior to cytarabine injection. After 2 weeks, the submandibular salivary glands were dissected out and prepared for histological and electron microscopic (TEM) examinations.

Results: Light microscopic examination of cytarabine group revealed deformity of the secretory portions with numerous intracellular vacuoles, deeply stained atrophied nuclei. Dilated excretory ducts with degenerated epithelial lining. Some secretory cells were completely degenerated. While Royal jelly treated group revealed well defined serous acini and well formed striated ducts. TEM examination of cytarabine group revealed pyknotic nuclei with nuclear polymorphism. Swollen mitochondria and dilated RER. Striated duct has ill-defined cell boundaries and cytoplasmic vacuolizations. These changes were more improved with Royal jelly treated group group.

Conclusion: Administration of Royal jelly produced a protective effect against cytotoxic changes induced by chemotherapy in rat submandibular salivary glands.

KEYWORDS: cytarabine, Submandibular salivary gland, royal jelly, light microscope, electron microscope

\footnotetext{
* Lecturer of Oral Biology Department Faculty of Dental Medicine for Girls AL-Azhar University.
} 


\section{INTRODUCTION}

Cancer is a major health problem worldwide and consider as one of the leading causes of human mortality, being the second reason of global spontaneous mortalities after cardiovascular diseases (Dawood et al., 2020). Cancer treatment was subjected to an important progress in last few years, when the oncology approaches had improved significantly for numerous patients. These patients whom suffered previously from chemotherapeutic drugs failures are now getting a better result with the reduced progression of cancer as well as increasing the rate of survival (Al-Jammas1 and Al-Saraj, 2020).

Cytarabine is a chemotherapy drug antimetabolite used mainly in treatment of cancers of white blood cells (WBCs) just like Non-Hodgkin lymphoma, acute Myeloid Leukemia, acute lymphocytic leukemia, chronic myelogenous leukemia (Dawood et al.,2020).Also, it used as an antiviral agent against herpes simplex virus and human cytomegalovirus It is a cell-phase-specific drug, primarily act during the $S$ phase when cells are undergoing DNA synthesis It causes extensive chromosomal destruction through induction of chromatid aberrations. Thus rapidly dividing cells, which need DNA replication for mitosis, are mostly affected (Konda et al., 2013, Ma et al., 2017)

The synthetic drugs in use for treatment of cancer are not only expensive but have complicated mode of intake and have several side effects. Therefore the search for alternative therapy has been advocated for. Natural products with anti-oxidant and anti-inflammatory activities are known to exhibit protection against the toxicities of chemotherapy (Attalla et al., 2014). Because the management of cancer without any side effects is still a challenge to the modern medicine, This leads to increase the demand for searching new drugs from natural origin with anticancer and free from side effect or less side effects.
Some of these natural products is royal jelly (RJ) which was reported to have a wonderful complex mixture of free amino acids, vitamins, proteins, sugars, minerals ( $\mathrm{Fe}, \mathrm{Na}, \mathrm{Ca}, \mathrm{K}, \mathrm{Zn}, \mathrm{Mg}, \mathrm{Mn}$, and $\mathrm{Cu}$ ) and fatty acids. Also it was rich by phenols, acetylcholine, steroids, and other component which making it highly recommended to use not only in prophylactic and therapeutic purpose but also in cosmetics for its alleged tonic and bio stimulating action (Mobasseri et al., 2015, Kausar et al., 2017, Saboor et al., 2020)

A protective role against oxidative damages due to its antioxidant potency and free radical scavenging capacity (Cemek et al., 2010). Royal jelly is a secretion produced by the hypopharyngeal and mandibular glands of worker honey bees (Apis mellifera). Inoue et al. reported the ameliorative role of dietary RJ on DNA oxidative damage in mice (Inoue et al., 2003). Moreover, RJ has shown neuroprotective effects in stress-induced animal models (Teixeira et al., 2017), aging (Pyrzanowska et al., 2014), and drug-induced neurotoxicity (Mohamed et al., 2015). Although it has been reported that $\mathrm{RJ}$ exhibited protective effect against carbon tetrachloride-induced hepatotoxicity (Cemek et al., 2010) and cisplatin-induced nephrotoxicity (Silici et al., 2011).

In the present study, we investigated the pathological effects of cyatabrine on rat salivary gland toxicity and the possible protective role of royal jelly to alleviate these side effects at both structural and ultrastructural levels.

\section{MATERIALS AND METHODS}

\section{Ethical statement}

The study protocol and the procedure for animal care and experiments were approved by research ethics committee of the faculty of Dentistry, Al Azhar University for Girls. Code REC-PD-21-03. 


\section{Material}

Royal jelly: RJ 1000 mg capsules were obtained from Pharco Pharmaceuticals, Alexandria, Egypt.

Cytarabine was obtained from ACDIMA International (AiT) Shanghai Xudong Haipu Pharmaceutical Co., Ltd.

Experiments were occur by 21 albino Wister rats $(220-250 \mathrm{~g})$ 8-to 12-weeks old obtained from laboratory animal's colony, Faculty of Veterinary Medicine, Cairo University, Egypt. The rats were housed both prior to and during the experimental procedures under a specific pathogen-free barrier system and kept on sterilized filter top cages with controlled humidity (50\%-60\%), (12-hour light/12hour dark regimen), at $20-24^{\circ} \mathrm{C}$. Animals were monitored daily (to avoid unnecessary pain and suffering). Rats were divided randomly into:

Group I (control group) normal G without any medication

Group II (cytarabine group) (7 rats) which given daily intraperitoneal dose injection of Cytarabine at dose $(100 \mathrm{mg} / \mathrm{kg}$ ) (Teixeira et al., 2017), for five days (Dawood et al., 2020)

Group III (cytarabine the same does previously \& Royal jelly (at a dose of $100 \mathrm{mg} / \mathrm{kg}$ body weight by gastric tube daily for 2 weeks) (Mostafa et al., 2020). (7 rats) was administrated royal jelly prior to cytarabine injection

One day after the last injection, the rats of all groups were euthanized by $\mathrm{CO}_{2}$ asphyxiation followed by cervical dislocation and the submandibular salivary glands were dissected out. After the glands of the right side were excised, those of the right side were fixed immediately in $10 \%$ neutral buffered formalin. Then, the specimens were washed properly under running water, dehydrated through ascending concentrations of alcohol and transferred to xylene to clear the specimens from alcohol. Then, the glands were embedded in paraffin wax and mounted in the center of the paraffin wax blocks. Sections from paraffin-embedded tissue blocks were cut 5 microns thick and mounted on glass slides for histological examination using H\&E stain

\section{Ultra- thin section of salivary gland}

Small pieces of average size one $\mathrm{mm} 3$ from salivary gland using a very sharp blade then rapidly fixed in a solution of $3 \%$ phosphate buffered gluteraldehyed for 1-2 hours (primary fixation). The specimens were washed and then fixed in $1 \%$ buffered osmium tetroxide at $4^{\circ} \mathrm{C}$ for $1-2$ hours. Dehydration in the ascending concentration of ethanol (50\% - 70\% - 90\%) occurred and then embedded using fresh epoxy resin in oven - dried gelatin capsules. Semithin sections (1-2 microns) were cut and stained with toluidine blue to examine by light microscope for localization of the target site. Ultrathin sections (0.06 microns) were cut using ultra microtome and glass knives then mounted on copper grids.Final examination was carried out using the transmission electron microscope (JEOL 1000) at different magnifications and photographed using C.C.D electron microscope unit (TEM) at National Research Centre, Dokki, Cairo, Egypt

\section{RESULTS}

\section{Light microscopic results}

\section{Group I:}

Examination of haematoxylin and eosin stained sections of this group showed normal architecture of acinar and ductal cells. The secretory terminal portions predominantly of the serous cells composed of pyramidal cells with basophilic cytoplasm which surrounding a narrow lumen and mucous cells composed of flattened cells with wide lumen and clear cytoplasm. The duct system has intercalated and striated ducts that have a wider lumen compared to intercalated ducts and low columnar cells with centrally placed nucleus and basal striation. Granular 
convoluted tubules characterized by their columnar cells containing secretory granules. (Fig.1A\& B).

\section{Group II}

Histological examination this group showed focal loss of the normal gland architecture. The secretory acini showed reduction in size and vesiculation. The acini cells had deeply basophilic nuclei (pyknotic and hyperchromatic nucleus) and some variability in their size were seen in some cells. Also, they revealed progressive vacuolization with variable sized vacuoles. The connective tissue septa containing dilated inter acinar blood vessel (congested) engorged with RBCs with many areas of extravasation. Distortion and loss of some acini and ducts were noticed.

Striated ducts appeared shrunken with loss of its normal arrangment. Most of granular convoluted tubules showed signs of degeneration in the form of loss of granules, ill-defined outlines, cytoplasmic vacuolization and clumping of the cytoplasm. Stagnation of secretory material in some dilated ducts. The epithelial lining of excretory ducts appeared atrophic with loss of their pseudo-stratification. Loss of normal architecture of the secretory portion (Fig.1C\& D).

\section{Group III}

Haematoxylin and eosin stained sections of this group showed slight improvement of the arrangement of acinar cells in both serous and mucous as well as the ductal cells. A limited number of congested blood vessels were observed close to striated ducts. Similarity of the lining of excretory ducts to normal with vacuolations exhibited in certain areas (Fig.1E\& F).

\section{Electron microscopic results}

Electron microscopic examination of the rat submandibular salivary glands of Group I showed normal pyramidal cells with basal round nuclei which has dense areas of chromatin at the periphery of the nucleus and defined nuclear envelop, intact cell boundaries, normal intercellular canaliculi and accumulated secretory granules of varying sizes and density (Fig.2A\& B). Normal ductal cells (striated duct) with abundant mitochondria and normal nuclei (Fig.2C\& D).

Examination of (SMG) at this group II revealed alterations in the ultrastructure of the secretory terminal portions when compared to the control group. The acini appeared with Shrunken apoptotic (pyknotic) nuclei with nuclear polymorphism. The mitochondria appeared swollen with disintegrated cristae. The RER was seen grossly dilated, evidence of degranulation, and retained secretion in the cisternae of RER were associated with the destructed mitochondria. Dilated RER cisternae gave a vesiculated appearance to the cytoplasm. Moreover, the cytoplasmic vacuolizations occupying extensive areas at several sites (Fig.3A\& B). Striated duct have ill-defined cell boundaries and cytoplasmic vacuolizations (Fig.3C\& D).

The ultrastructural findings of group III, the glands of revealed improvement in the architectural features of the glands. The majority of acinar cells almost regained their normal architecture, the array of RER thrown in parallel sacs encircled the nucleus without any evidence of cisternae dilatation. The mitochondria with almost normal size were distributed all over the cytoplasm and the semicircular stacked flat sacs of the Golgi apparatus were interposed between the array of RER and the secretory granules. The nucleus displayed normal regular arrangement of dispersed chromatin together with a central round nucleolus with no or slight evidence of chromatin margination and clumping. The extensive vacuolization was no more detected apart from few microvesicles appearing in the cytoplasm of some specimens (Fig.4A\& B). Striated ducts regained their normal histological appearance, with the columnar cells having numerous basally located radially arranged rod-shaped mitochondria with minimal changes (Fig.4C\& D). 

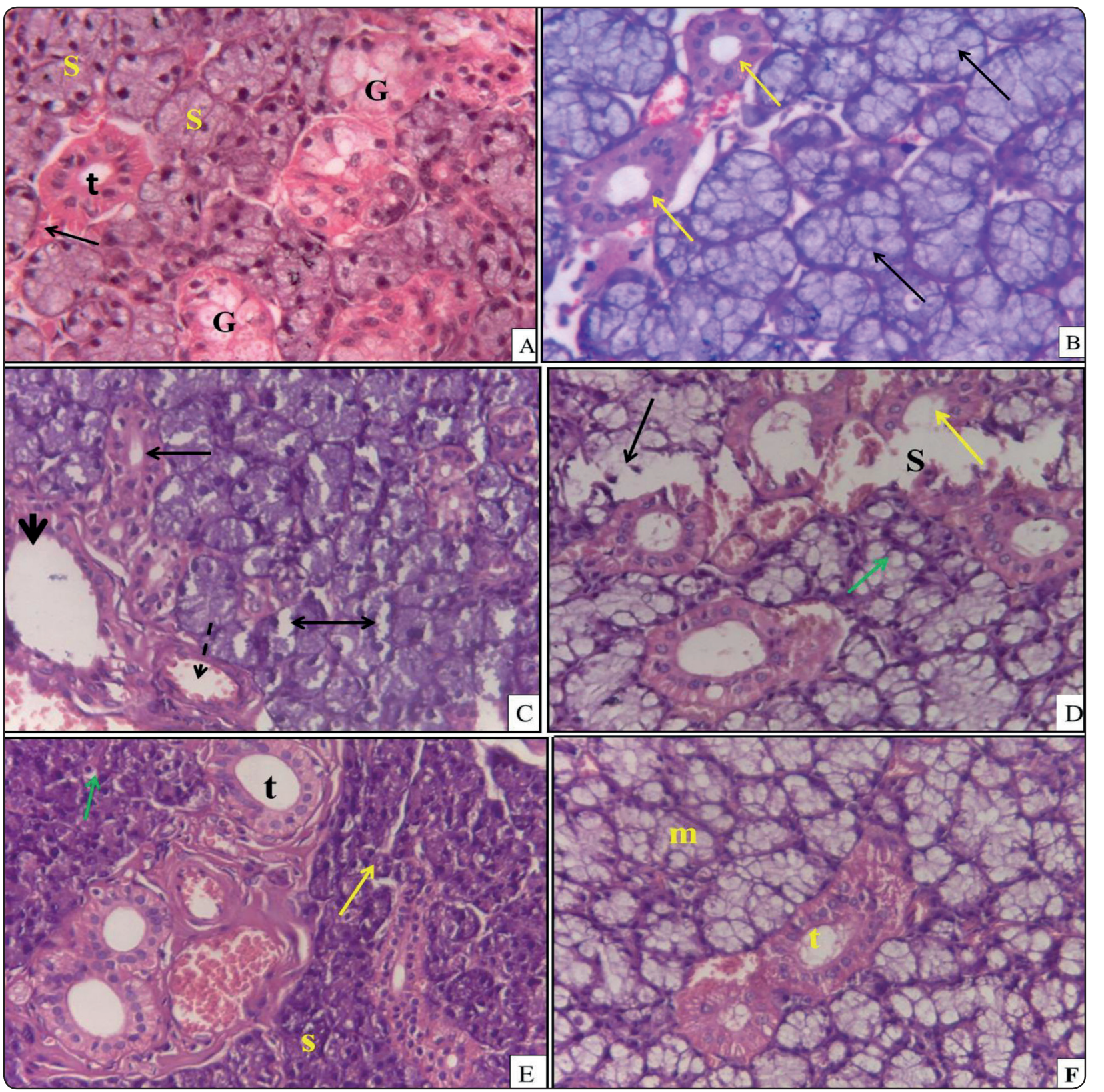

Fig. (1) Photomicrographs of Submandibular gland of rat showing: (A\&B) control group, normal gland architecture. (A) Serous cell with Serous acini, lined by pyramidal cells and basal rounded nuclei(s) and granular convoluted tubules (g), striated ducts lined by columnar cells with basal striations $(\mathrm{t})$. Some blood vessels appear in the connective tissue stroma around the ducts (arrow). (B) Normal architecture of mucous acini (black arrows) with duct system composed of striated ducts (yellow arrows). (C\&D) group II, (C) Abnormal shape of serous acini with indistinct boundaries and vacuolation of the cytoplasm (double arrow), dilated striated duct (arrow) and excretory ducts (arrow head) and congested blood vessel with extravagated RBCs (dashed arrow), (D) the completely destroyed mucous acini (black arrow), striated duct (yellow arrow), the remaining acini lacked their normal architecture (green arrows). (E\&F) group III, (E), normal histological features of serous acini (s) and striated duct $(\mathrm{t})$ with minor atrophy of some acini (yellow arrows), and few cytoplasmic vacuolization (green arrows). $(\mathrm{F})$, normal form and arrangement of mucous acini $(\mathrm{m})$ and striated duct $(\mathrm{t})$ with few cytoplasmic vacuolization (Original magnification x 200). 


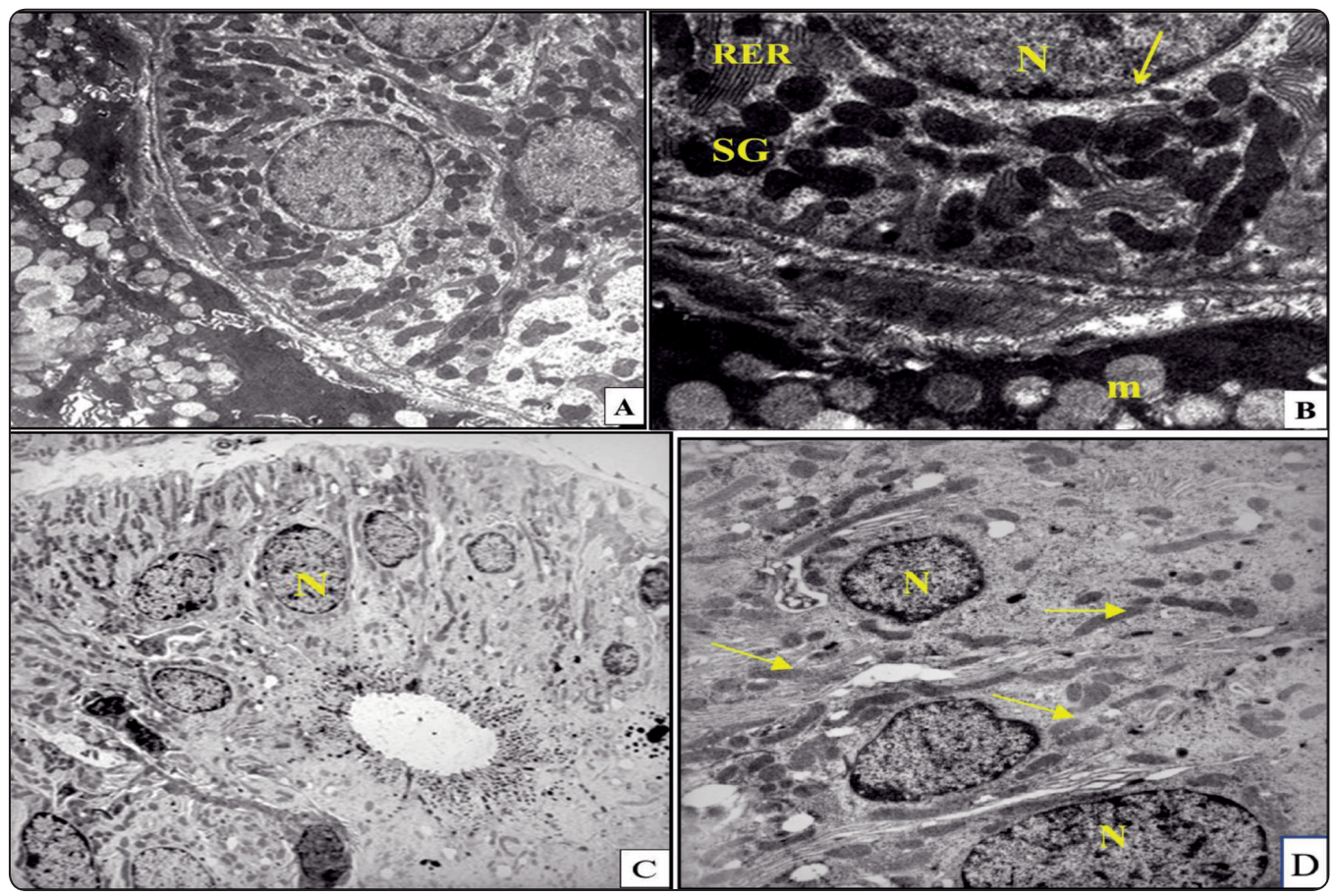

Fig.(2): An electron micrograph of the serous acini, group I showing, (A) serus acini with normal cell relationship and intact cell boundaries, (B) serous acinar cell have nucleus (N), nuclear membrane (arrows), numerous secretory granules (SG). mitochondria $(\mathrm{m})$ with prominent cristae in their inner membrane and flattened cisternae of rough endoplasmic reticulum (RER). (C) Striated duct with columnar epithelial cells lining the duct have prominent normal nuclei (N). (D) higher magnification of the previos figure showing normal nuclei $(\mathrm{N})$ and abundant mitochondria (arrows) . (TEM- Orig. Mag. A\&CX1000, B\&DX 2000).

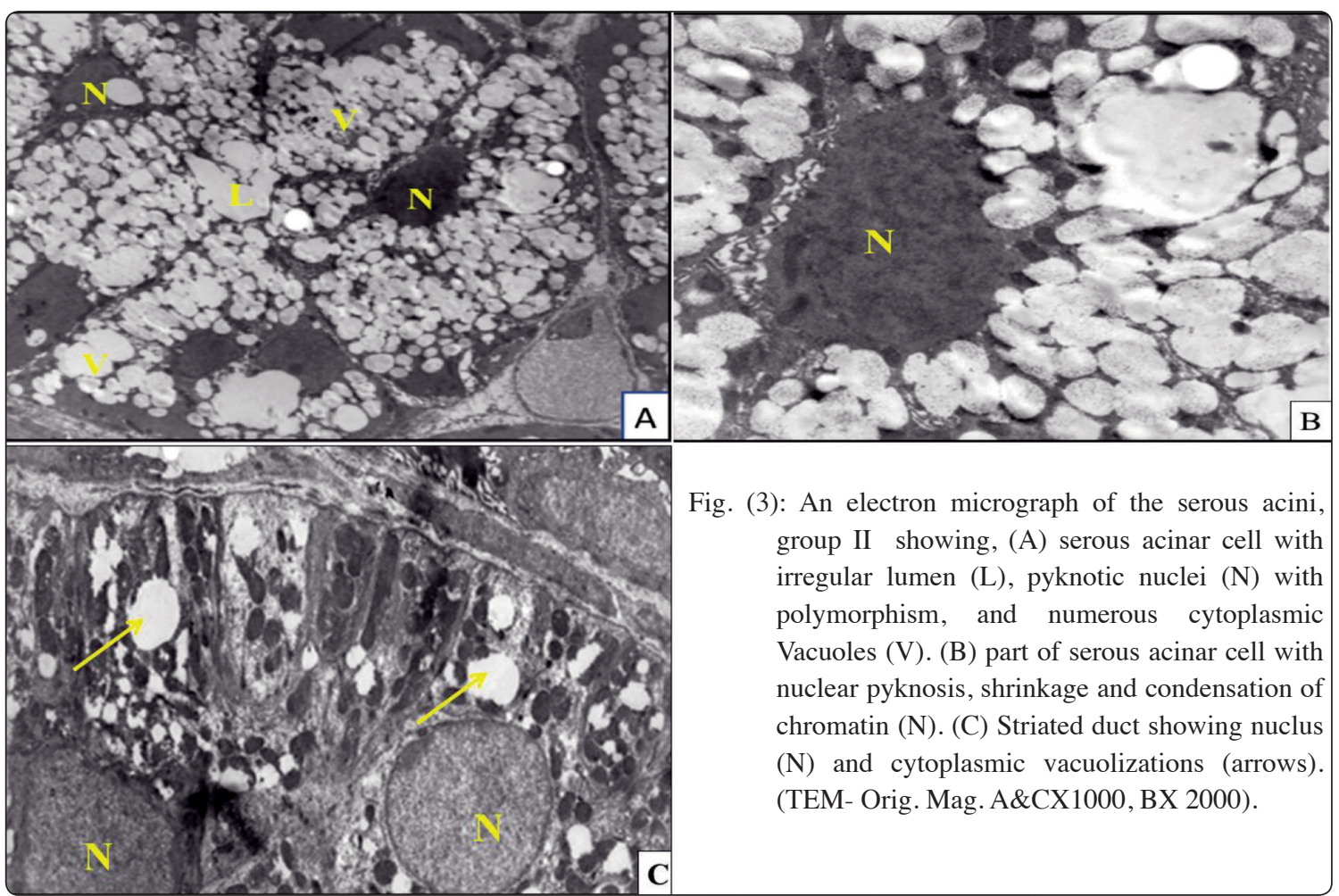




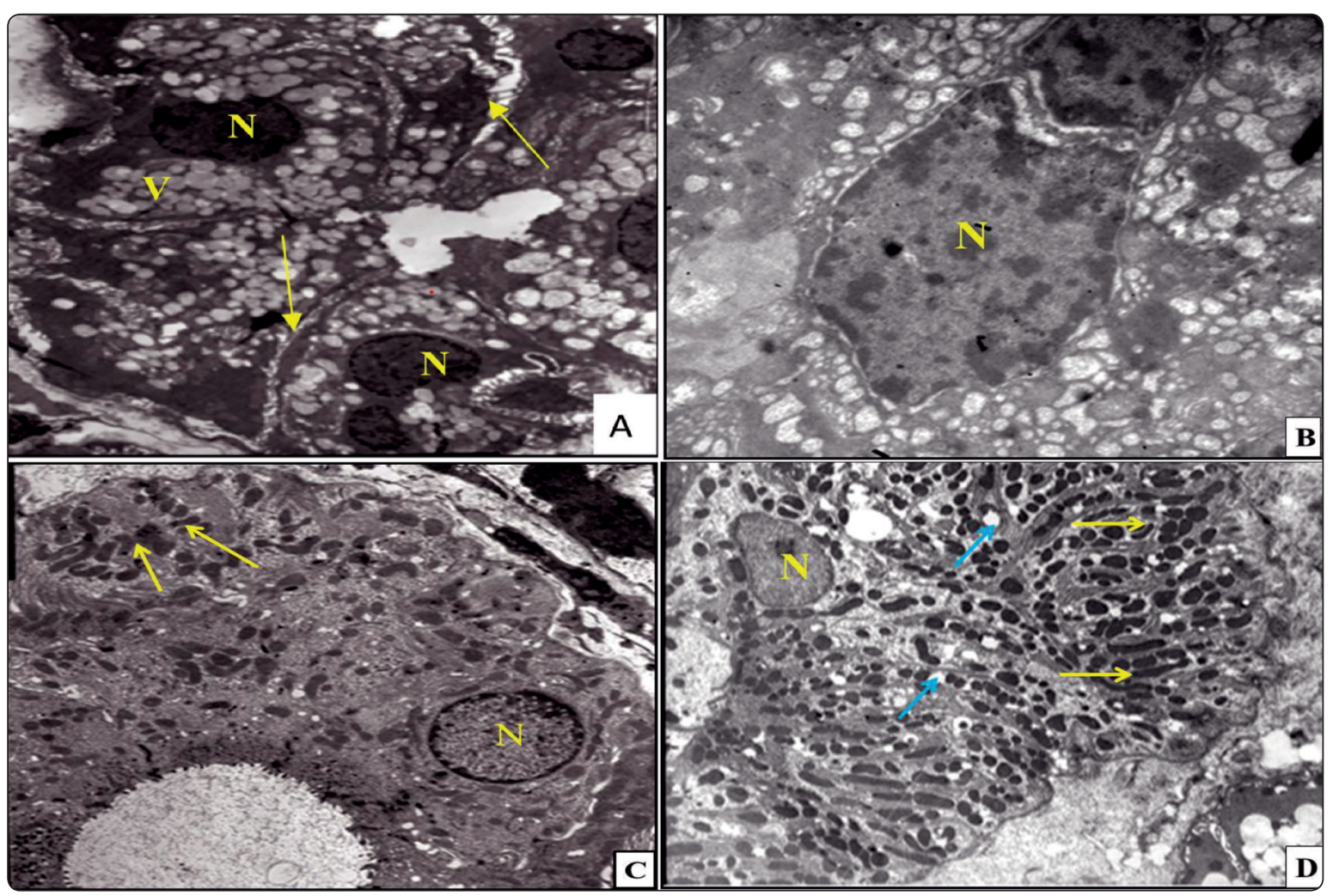

Fig.(4): An electron micrograph of the serous acini, group III showing, (A) serous cell with intercellular spaces (arrows), pyknotic nuclei $(\mathrm{N})$, many cytoplasmic vacuoles $(\mathrm{V})$ causing indentation of the nucleus. (B) part of serous acinar cell showing nucleus $(\mathrm{N})$. (C) Striated duct showing normal nucleus (N), numerous mitochondria (arrows), (D) part of Striated duct showing abundant mitochondria (yellow arrows) and few cytoplasmic vacuolizations (blue arrows) (TEM- Orig. Mag. A\&CX1000, B\&DX 2000).

\section{DISCUSSION}

Chemotherapy targeting both normal and tumor cells. Salivary gland almost affected results in a variety of side effects. This study attempted to clarify the adverse effects of cytarabine (chemotherapeutic drug) on rat's submandibular salivary glands and the possible role of royal jelly to alleviate these effects.

The results of this current study coincided with previous study of pathophysiology behind xerostomia and reduced function of the salivary glands during and after chemotherapy and mentioned that Antimetabolites chemotherapy (5-fluorouracil, methotrexate and cytarabine) cause nuclear degeneration, vacuolization, ductal dilatation, inflammation, cyst formation and reduced salivary flow rate (Jensen $e t$ al., 2003, Kitashima, 2005, Özel et al., 2010).
Histological section of SG in cytarabine group showed abnormal salivary architecture and defused vacuolar area. Also there were blood vessels and multiple foci of apoptotic cells and minimal inflammatory response were noticed. This current result was explained by oxidative damage due to presence of (ROS) (reactive oxidative stress) that leads to mitochondrial DNA damage (mtDNA) and those changes related to DNA fragmentation and apoptosis initiation (Mustafa et al., 2015)

Cytarabine also acts through direct DNA damage then cytokines enter the circulation and activate an inflammatory cascade. Both intrinsic and extrinsic apoptotic pathways are up regulated and mucosal integrity is damaged by inflammatory infiltrates and tight junction interruption (Marcussen et al., 
2017). Moreover, chemotheapy is activated as soon as it enters the cell. are displaced by water molecules displace the chloride atoms on cisplatin, this hydrolyzed product can react with any nitrogen donor atom on the nucleic acid causing DNA damage, blocking cell division and lead to nonselective apoptosis which affects tumor cells and normal cells as well (Shaloam and Paul, 2014).

Also chemotherapy affects salivary glands function leading to temporary or permanent dysfunction that can result in saliva secretion reduction and inadequate composition. In addition chemotherapy affect microflora diversity and load; this imbalance responsible for opportunistic infections or the reactivation of latent viruses (Hey et al., 2009, Wojciechowicz et al., 2018).

This result in the same line with that occured after 1 dose of 5-fluorouracil chemotherapy induced similar changes on sub mandibular salivary gland of rabbits and also reported that the severity and prevalence of pathological changes increased as chemotherapeutic doses increased (Özel et al., 2010, Merhan and Enas, 2020).

Several medicinal plants are used for the treatment of various diseases comprising tumors that are becoming critical for drug discovery and clinical application and research (Dutta et al., 2018, Sadhukhan et al., 2018). These natural phytochemicals are established to be efficient toward various kinds of tumors. Royal jelly, and bee grain pollen can be used to counteract the cytotoxicity of 5-Furacil and consequently reduce the toxicity of 5-furacil for overcoming the breast cancer and their metastasis and their actions may be due to the phytochemical constituents in the honey, particularly phenolic compounds (Lina, 2020).

Interestingly, royal jelly treated groups showed marked improvement in gland architecture which appeared in the hematoxylin and eosin and also in the electron microscopic results. The result was in accordance with (Mohammadi et al., 2018) which found that RJ can be used as a cytotoxic agent for cancer treatment. It has been reported that 10-hydroxy-decenoic acid is one of the major organic acids in RJ composition. It seems that the anti-tumor activity of whole $\mathrm{RJ}$ is attributed to this organic acid.

This improvement could be attributed to the beneficial antioxidant activity of royal jelly, which could be explained by its high content of polyphenolic enriched fractions which act as antioxidant. This effect may be due to its elevated antioxidant capacity to inhibit ROS production by stopping the activation of the cytosolic component of NADPH oxidase, one of the major intracellular sources of ROS, or by neutralizing the free radicals by transferring either electrons or hydrogen atoms (Cemek et al., 2010, Shinichi et al., 2013, Mobasseri et al., 2015).

Studies have suggested that RJ efficiently inhibits the production of pro-inflammatory cytokines such as TNF $\alpha$, IL-1, and IL- 6 by lipopolysaccharideand interferon gamma-stimulated macrophages. Therefore, a mucosal-protective effect and a tissue repair-promoting action might be involved in the mechanism of the healing effect of RJ (Shinichi et al., 2013).

\section{CONCLUSION}

The results of this study indicate that royal jelly (RJ) causes satisfactory recovery in chemotherapyinduced salivary gland toxicity. Further studies may reveal important information about the pathogenesis and treatment by RJ of salivary gland diseases.

\section{Recommendations}

Chemotherapeutic drugs had damaging effects on oral tissues so, Further investigations will be required to evaluate the ability of anti-oxidant agent to decrease the cytotoxic effects of chemotherapy. 


\section{REFERENCES}

1. Al-Jammas1 S, and Al-Saraj A. The histological changes induced by Cytarabine on rabbits livers (with and without vitamin E administration). Iraqi J. of Vet. Sci., 34: 9-13, 2020

2. Attalla F, El-Kott Nahed A, Omar And Seham E. The Protective Effect of Royal jelly Against Doxorubicin-induced Renal Oxidative Stress, Histopathological and Immunohistochemiacal Alterations in Ehrlich Ascites Tumor Bearing Mice. Mansy. Egypt. Acad. J. Biolog. Sci., 5: 9-21, 2014

3. Cemek M, Aymelek F, Büyükokuroğlu ME, et al. Protective potential of Royal Jelly against carbon tetrachloride induced toxicity and changes in the serum sialic acid levels. Food and chemical toxicology; 48: 2827-2832, 2010.

4. Dawood Gh A, Taqa Gh A and Alnema M. Histological Effect of Cytarabine on Liver and Buccal Mucosa in Mice. Al-Rafidain Dent J., 20: 36-45, 2020

5. Dutta S, Saha S, Mahalanobish S, Sadhukhan P and Sil PC. Melatonin attenuates arsenic-induced nephropathy via the regulation of oxidative stress and inflammatory signaling cascades in mice. Food Chemical Toxicology., 118: 303-316, 2018

6. Hey J, Setz J, Gerlach R, Vordermark D, Gernhardt CR and Kuhnt T. Effect of Cisplatin on parotid gland function in concomitant radiochemotherapy. Int. J. Radiat. Oncol. Biol. Phys., 75: 1475-1480, 2009

7. Inoue SI, Miyata SK, Ushio S, Iwaki K, Ikeda M and Kurimoto M. Royal Jelly prolongs the life span of $\mathrm{C} 3 \mathrm{H} / \mathrm{HeJ}$ mice: correlation with reduced DNA damage, Experimental. Gerontology., 38: 965- 969, 2003;

8. Jensen S, Pedersen A, Reibel J and Nauntofte B. Review article (xerostomia and hypofunction of the salivary glands in cancer therapy). Support Care Cancer.,11:207-225, 2003

9. Kausar SH, More VR and Ali SR. Spectrophotometric analysis of total protein content in fresh and lyophilised royal jelly. J. med. chem. drug discov., 3: 442-450, 2017

10. Kitashima S. Morphological alterations of submandibular glands caused by cisplatin in the rat. The Kurume Med J., $52: 29-38,2005$

11. Konda N, Prashanth P, Arvind G, and Shah S. Pharmaceutical development and compatibility studies on cytarabine injection. Asian J Pharm Clin Res., 6 : 142-145, 2013
12. Lina K. Cytotoxicity effect of 5-fluorouracil and bee products on the MCF-7 Human Breast Cancer Cell Line in vitro. International Journal of Pharmaceutical and Phytopharmacological Research (eIJPPR)., 2 :19-26, 2020

13. Ma J, Li X, Su Y, et al. Mechanisms responsible for the synergistic antileukemic interactions between ATR inhibition and cytarabine in acute myeloid leukemia cells. Sci. Rep., 7 :41-50, 2017

14. Marcussen M, Skrubbeltrang C, Bødker J, et al. A systematic review of molecular responses to cancer therapy in normal human mucosa. Oral Surg, Oral Med, Oral Pathol and Oral Radiol Endod., 124 : 355-366, 2017

15. Mobasseri M, Ghiyasvand S, Ostadrahimi A, Ghojazadeh M, Noshad H and Pourmoradian S. Effect of fresh royal jelly ingestion on glycemic response in patients with type 2 diabetes. Iran Red Crescent Med J., 17 :1-5, 2015

16. Merhan NE and Enas MH. Evaluation Of The Apoptotic Changes Induced By 5-Fluorouracil On The Lingual Mucosa And Salivary Glands Of Male Albino Rats (Histological, Histomorphometric And Immunohistochemical Study). Egypt Dent J., 66, 4: 2353-2363, 2020

17. Mohamed AA, Galal AA and Elewa YH. Comparative protective effects of royal jelly and cod liver oil against neurotoxic impact of tartrazine on male rat pups brain. Acta Histochem., 117 :649-658, 2015

18. Mostafa RE, El-Marasy SA, Abdel Jaleel GA and Bakeer RM. Protective effect of royal jelly against diclofenacinduced hepato-renal damage and gastrointestinal ulcerations in rats. Heliyon., 6: e0330, 2020

19. Mohammadi AR, Parsian H, Kazerouni F, et al. Effect of Simultaneous Treatment with Royal Jelly and Doxorubicin on the Survival of the Prostate Cancer Cell Line (PC3): An In Vitro Study. Int. j. cancer manag., 11: 137-144, 2018

20. Mustafa N, El Awdan A, Hegazy A and Abdel Jaleel A. Prophylactic role of coenzyme Q10 and Cynara scolymus $\mathrm{L}$ on doxorubicin-induced toxicity in rats: Biochemical and immunohistochemical study. Indian j. of pharmacol., 47: 649-656, 2015

21. Özel O, Ayçiçek A, Kenar F, et al. Histopathologic changes in the rabbit submandibular gland after 5-fluorouracil chemotherapy. Turk. J. of Med. Sci., 40 :213-220, 2010

22. Pyrzanowska J, Piechal A, Blecharz-Klin K, Joniec-Maciejak I, Graikou K and Chinou I. Long-term administration of Greek Royal Jelly improves spatial memory and 
influences the concentration of brain neurotransmitters in naturally aged Wistar male rats.J Ethnopharmacol., $155: 343-351,2014$

23. Saboor A, Maria G, Filippo F, Solomon ZA and Jianke Li New Insights into the Biological and Pharmaceutical Properties of Royal Jelly. Int. J. Mol. Sci., 21: 382-390, 2020

24. Sadhukhan P, Saha S, Dutta S and Sil PC. Mangiferin ameliorates cisplatin-induced acute kidney injury by upregulating nrf-2 via the activation of PI3K and exhibits synergistic anticancer activity with cisplatin. FRONT PHARMACOL., 9: 638-644, 2018

25. Shaloam D and Paul BT. cisplatin in cancer therapy: molecular mechanisms of action. Eur. J. Pharmacol., 45: 364378,2014
26. Shinichi W, Katsuya S, Kenshi T, Hiroaki K, Kimie I and Hiroaki A. Oral Mucosal Adhesive Films Containing Royal Jelly Accelerate Recovery From 5-Fluorouracil-Induced Oral Mucositis. J. Pharmacol. Sci., 121: 110 - 118, 2013

27. Silici S, Ekmekcioglu O, Kanbur M and Deniz K. The protective effect of royal jelly against cisplatin-induced renal oxidative stress in rats. World J. Urol., 29: 127-132, 2011

28. Teixeira RR, de Souza AV, Peixoto LG, Machado HL, Caixeta DC and Vilela DD. Royal jelly decreases corticosterone levels and improves the brain antioxidant system in restraint and cold stressed rats. Neurosci. Lett., 655: 179-185, 2017

29. Wojciechowicz J, Kostyra M, Kozińska J, Hus M and Tomaszewski T. Oral mucositis in patients with leukaemia following high-dose chemotherapy and autologous toward solid tumors. Int. J. Pharm., 552 :111-118, 2018 